\title{
Melatonin reduces the severity of experimental amoebiasis
}

\author{
Aline C França-Botelho ${ }^{1,2}$, Juliana L França ${ }^{2,3}$, Fabrício MS Oliveira ${ }^{4}$, Eduardo L Franca ${ }^{5}$, \\ Adenilda C Honório-França ${ }^{5}$, Marcelo V Caliari ${ }^{4}$ and Maria A Gomes ${ }^{1 *}$
}

\begin{abstract}
Background: Melatonin has immunomodulatory effects but very little is known about its influence in protozoan infections, such as Entamoeba histolytica, which causes amoebiasis, a disease with significant morbidity and mortality. In this study, we evaluated the effects of exogenous melatonin interference in experimental amoebiasis and on interactions between human blood cells and E. histolytica trophozoites.

Methods: The effect of melatonin was investigated in models of experimental amoebiasis in hamsters and rats by evaluating the area of necrosis induced by E. histolytica. The activity of melatonin on the interactions between leukocytes and amoebae was determined by examining leukophagocytosis. For in vitro tests, polymorphonuclear and mononuclear human blood leucocytes were incubated with E. histolytica trophozoites.
\end{abstract}

Results: The areas of amoebic necrosis were significantly reduced in animals treated with melatonin. Melatonin treatment increased leukophagocytosis but was associated with a greater number of dead amoebae.

Conclusions: These results suggest that melatonin may play a beneficial role in the control of amoebic lesions, raising the possibility that this drug may be used as an adjuvant in anti-amoebic therapy.

\section{Background}

Melatonin [N-acetyl-5-methoxytryptamine] is an indoleamine synthesised from tryptophan. The physiological properties of melatonin are not limited to its neuroendocrine role in controlling circadian rhythms [1]; several other actions have been discovered. Melatonin has been shown to increase innate and acquired immunity [2], to activate the bone marrow and lymph nodes [3], to enhance NK cell activity $[4,5]$ and antibody-dependent cell cytotoxicity [6], to increase $\mathrm{T}$ cell proliferation in vivo and in vitro $[7,8]$ and to activate monocytes $[9,10]$ and neutrophils [11].

Melatonin can stimulate innate immune cells, primarily leukocytes, which represents an important anti-bacterial mechanism $[12,13]$; however, very little is known about its influence on protozoan infections.

Entamoeba histolytica is an enteric protozoan parasite that infects 500 million people, causes amoebiasis in 50 million and kills 100000 individuals annually, thus

\footnotetext{
* Correspondence: magomes@icb.ufmg.br

'Department of Parasitology, Institute of Biological Sciences, Universidade

Federal de Minas Gerais, Belo Horizonte, Minas Gerais, Brazil

Full list of author information is available at the end of the article
}

constituting a serious health public problem [14]. The disease is widely distributed worldwide, but its incidence is highest in places with insufficient basic sanitation. Several aspects of this host parasite relationship, such as parasite virulence and host susceptibility, are poorly understood. The course of infection begins with an inflammatory process that recruits eosinophils, lymphocytes, neutrophils and macrophages [15]; however, despite this immune cell recruitment, tissue destruction progresses, generating a typical amoebic necrotic area.

Melatonin has been reported to have immunomodulatory effects in the cases of toxoplasmosis [16-18], malaria [19,20] and Chagas disease [21].

One of these studies investigated the effect of melatonin and zinc on the immune response to Toxoplasma gondii retinochoroiditis in the rat model (pinealectomy or not) of infection and to establish the possible value of supplementation as adjunctive therapeutic agents in the treatment of T. gondii retinochoroiditis. Melatonin should be considered as an adjunctive therapy to classic treatment of Toxoplasma retinochoroiditis, especially in immunosuppressed and elderly patients if our data are confirmed in a clinical setting [18]. 
In model Chagas disease, animals treated with melatonin showed a significant reduction in the number of blood trypomastigotes during the acute phase of infection compared with untreated animals and increase in leucocytes numbers during the peak of parasitaemia [21].

Nothing has yet been reported regarding amoebiasis. This pioneering study aims to evaluate the influence of exogenous melatonin in experimental amoebic infections and its effects on amoebae-leukocyte interactions in vitro.

\section{Results}

In vivo results

E. histolytica-infected hamsters that were treated with melatonin exhibited significantly reduced areas of hepatic necrosis relative to those in the control group ( $<<$ $0.05)$. The necrotic areas in the melatonin-treated animals were about half the size of the lesions in the untreated animals (Figure 1). Furthermore, only 1 of the 6 rats treated with melatonin showed amoebic lesions in its caecum, whereas 5 of the 6 untreated rats had caecal lesions.

Figure 2 shows the histopathological analysis of hamsters inoculated with the HM1 strain of E. histolytica either without ( $\mathrm{a}$ and $\mathrm{b}$ ) or with melatonin treatment ( $\mathrm{c}$ and d). The area of tissue destruction was smaller in animals that were treated with melatonin than in controls that did not receive melatonin treatment. Microscopic observation of hepatic tissues from animals that did not receive treatment showed that necrosis was often distributed over wide areas. In contrast, necrotic regions were interspersed between areas of normal tissue in animals that received melatonin treatment. The inflammatory infiltrate was more intense in the treated animals and showed focal zones comprised of large numbers of mononuclear cells and some giant cells.

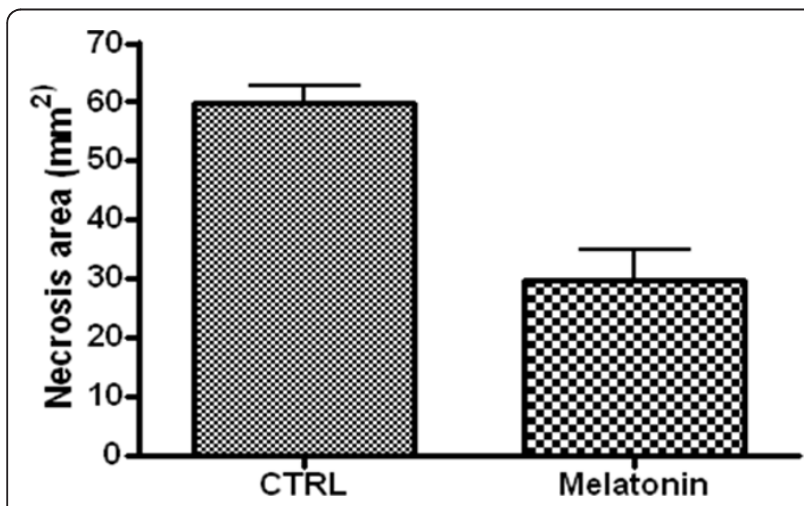

Figure 1 Amoebic hepatic necrosis. Amoebic hepatic necrosis in $\mathrm{mm}^{2}$ and standard deviation in hamsters treated and not treated with melatonin.

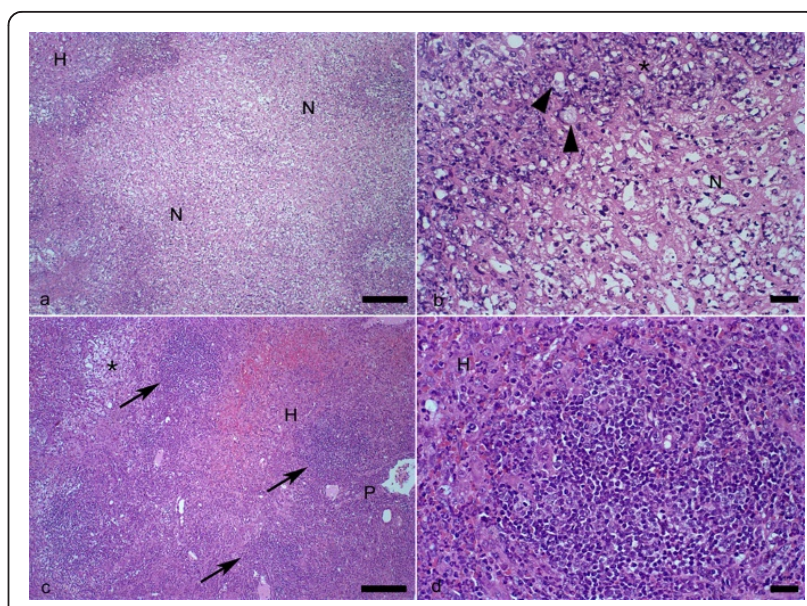

Figure 2 Histology of liver from hamsters. Histology of liver from hamsters inoculated with the HM1 strain of E. histolytica. (a) significant necrosis of the liver parenchyma $(\mathrm{N})$ of untreated hamster melatonin. Non-necrotic hepatic parenchyma $(H)$, (b) Detail of preceding figure showing trophozoites (arrowheads) adjacent to the large amount of cellular debris and moderate inflammatory infiltrate $\left(^{*}\right)$. Necrosis $(N)$, (c) non-necrotic hepatic parenchyma $(H)$ of hamsters that received melatonin. Note the presence of focal inflammatory infiltrate rich in mononuclear cells (arrows). Granulation tissue $\left({ }^{*}\right)$. Portal space (P), (d) Detail of previous picture showing one of the focal infiltrates predominantly composed of lymphocytes and macrophages. Non-necrotic liver parenchyma $(H)$. H\&E. (a) and (c) Bar $100 \mu \mathrm{m}$; (b) and (d) Bar $20 \mu \mathrm{m}$.

These focal zones were absent in animals that did not receive melatonin treatment.

\section{In vitro results}

Melatonin increased the adherence of E. histolytica trophozoites to mononuclear (MN) and polymorphonuclear (PMN) leukocytes." The highest adherence rate (80.4\%) was seen with $\mathrm{MN}$ cells in the presence of melatonin. In analysing the ingestion of leukocytes by the amoebae, we found that melatonin only induced a significant increase in the ingestion of PMN leukocytes: the ingestion rate was $50.6 \%$ in the absence of melatonin and $62 \%$ in its presence. We observed a significant increase in the percentage of dead amoebae during leukocyte internalization in the presence of melatonin, with the frequency of dead amoebae increasing by $26 \%$ for those ingesting MN leucocytes and 24\% for those ingesting PMN leucocytes, relative to those in non-melatonintreated cultures (Figures. 3a and 3b).

During phagocytosis, in the presence of melatonin, superoxide released from $\mathrm{MN}$ interacting with amoebae was $26.2 \mathrm{nmol}$ and PMN interacting with amoebae was $27.8 \mathrm{nmol}$. The controls were $10.4 \mathrm{nmol}$ and $16.6 \mathrm{nmol}$ respectively. SOD released from $\mathrm{MN}$ interacting with amoebae was 108.8 and PMN interacting with amoebae was 125.6. The controls in the absence of melatonin were 76.4 and 66.6 respectively. 


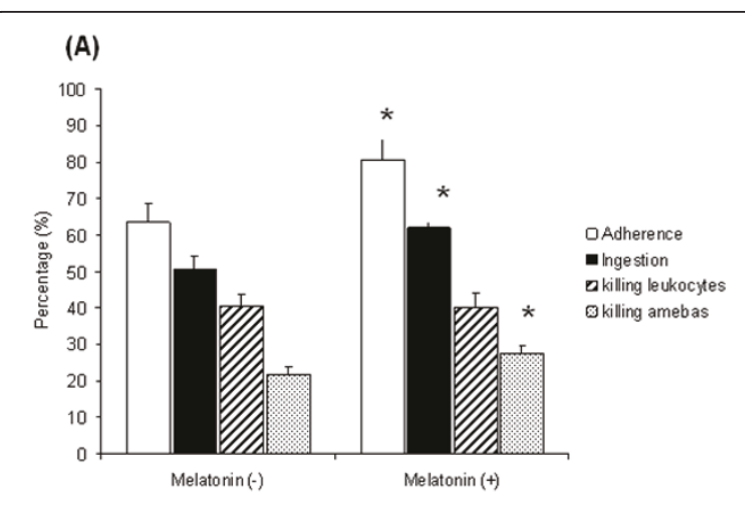

(B)

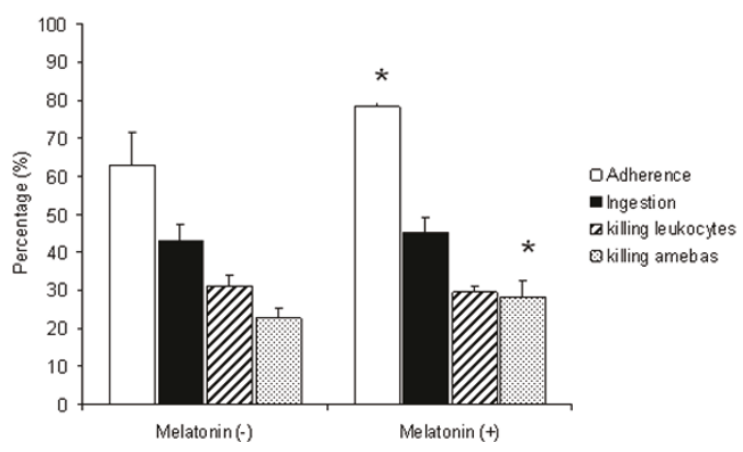

Figure 3 Leukophagocytosis. Effects of melatonin on leukophagocytosis of mononuclear (A) and polymorphonuclear (B) human leukocytes accomplished by amoebae, evaluated by the parameters: adherence, leukocytes ingestion, killing leukocytes and killing amoebae. Results are the percent means and standard deviation of 5 repetitions. Statistically different $(p<0.05)$ versus control (melatonin absent).

\section{Discussion}

Little is known about the immunomodulatory effects of melatonin in protozoan infections. This study is the first to evaluate the action of melatonin on E. histolytica in vivo and in vitro. The results of our experimental amoebiasis studies showed a significant reduction in the areas of amoebic necrosis in response to melatonin treatment. In the treated animals, areas of necrosis were often associated with large amounts of predominantly mononuclear inflammatory infiltrate, which suggests that melatonin likely induces Th1 immune responses, thereby containing the infection and reducing the size of liver abscesses.

Amoebae-derived substances are known to be important factors for tissue damage [22-24]. Therefore, the reduction of necrotic areas may also be related to parasite factors, such as proteinases and amoebapores, which may be present in smaller proportions in the areas treated with melatonin, given the reduced presence of trophozoites in these regions.

It is worth mentioning that hamsters were chosen as an experimental infection model because they are more susceptible to infection by $E$. histolytica than mice, and criteria for determining the severity of their injuries are well established, thus allowing differences resulting from the administration of melatonin to be better distinguished. Our results indicate that there are beneficial effects of exogenous melatonin, corroborating reports that have evaluated melatonin as a modulator of other parasitic infections [16-21,25].

In a model of schistosomiasis in hamsters, melatonin increases the efficacy of cercarial and soluble worm antigens in inducing protective immunity against infection, suggesting possible applications in a vaccination program [26]. Melatonin can synchronize the cycle of the malaria parasite; the rupture of infected erythrocytes coincides with the timed release of melatonin in vertebrates, which occurs between midnight and three a.m. [27].

Phagocytosis plays an important role in E. histolytica pathogenicity, making it an object of investigations. A comprehensive evaluation of the phagocytic capacity of amoebae involves leukophagocytosis because amoebae are constantly in contact with leukocytes in vivo and must be able to destroy them to survive.

The identification of substances involved in leukocyte activation during amoeba-leukocyte interactions would help to direct the appropriate therapeutic use of these substances in amoebiasis. In this context, we evaluated the action of melatonin, a known immunomodulator, during PMN and MN leukophagocytosis performed by E. histolytica trophozoites.

Classical studies involving amoebae and leukocytes $[28,29]$ have shown that virulent strains of amoebae are lethal for leukocytes, which lose their motility and are then phagocytosed and killed by the amoebae. In this study, we observed an increase in the rate of leukophagocytosis in the presence of the melatonin; however, this was accompanied by significantly higher rates of dead amoebae during the process. This suggests that melatonin plays a beneficial role for the host by activating PMN and MN cells. In addition, higher levels of superoxide anion and superoxide dismutase (SOD) were obtained during interactions in the presence of melatonin, which correlates with higher microbicidal leukocyte activity. Increased SOD may reflect antioxidant properties of melatonin which may be related to the reduced tissue damage.

These results suggest the need for further studies aiming to elucidate the mechanism of melatonin action in the host immune response. It would also be interesting to evaluate whether associations with other drugs may enhance the beneficial effects of melatonin in amoebiasis, as has been demonstrated for infections with Trypanosoma cruzi [30].

\section{Conclusions}

The reduction in the areas of necrosis observed in experimental amoebic infection of hamsters and rats, 
together with the increased death of amoebae during leukophagocytosis, suggests that melatonin may play a beneficial role in the control of amoebic lesions and indicates that, as in other diseases, melatonin may be useful as an adjuvant in anti-amoebic therapy.

\section{Methods}

All procedures were evaluated and institutionally approved by the Ethics Committee (protocol 6815/41), in compliance with the Helsinki Declaration and international guidelines for experimental research on animals.

\section{In vivo experiments}

Trophozoites of the virulent strain of E. histolytica HM1:IMSS were grown axenically in a TYI-S-33 medium [31]. Parasites were maintained with thrice-weekly sub-cultures, assuring their use in the exponential growth phase.

Amoebas from axenic cultures were centrifuged at 200 $\times \mathrm{g}$ in individual tubes, washed twice with PBS ( $\mathrm{pH} 7.2)$ and adjusted to $1 \times 10^{6}$ amoebae in $0.1 \mathrm{~mL}$ of inoculum.

Six hamsters (Mesocricetus auratus), intestinal amoebiasis model and and six Wistar rats (Rattus norvegicus) amoebic liver model [32] were used for each group of experiments. In the case of both species the animals were male and approximately 40 days old, with the hamsters weighing around $60 \mathrm{~g}$ and the rats weighing around $110 \mathrm{~g}$.

The animals were anesthetized with sodium pentobarbital (30 mg/kg for rats and $79 \mathrm{mg} / \mathrm{kg}$ for hamsters) and laparotomised, and the amoebae were inoculated directly into the liver (hamsters) or caecum (Wistar rats). Six days after inoculation, animals were sacrificed and dissected for macroscopic examination of the liver or caecum. Fragments of hamster livers and rat caeca were fixed in $10 \%$ buffered formalin, $\mathrm{pH}$ 7.2. After the fixation period, the fragments were dehydrated, diaphanised,[what is diaphanised? Do you mean cleared?] infiltrated and embedded in paraffin. Sections obtained for staining with hematoxylin and eosin (H\&E) were $4 \mathrm{~mm}$ [not mm surely??] thick.

Areas of amoebic liver necrosis were quantified using the KS300 software contained in the Carl Zeiss image analyser. For the evaluation of necrosis, the sections were examined "in totum" and all images of destroyed liver parenchyma were digitalised using a $4 \times$ or $10 \times$ objective lens and a JVC TK-1270/RGB micro camera. The caeca were examined under an optical microscope to assess the presence or absence of amoebic lesions.

The inoculated animals were treated with melatonin (Sigma, St. Louis, MO, USA) subcutaneously [33] at a dose of $15 \mathrm{mg} / \mathrm{kg}$ body weight [34]. The drug was dissolved in deionised water and given once a day during the six days of the experiment. Treatment was started on the same day as the infection. All procedures for handling melatonin occurred in a darkened room.

\section{In vitro experiments}

After obtaining written consent, heparinised blood was obtained from 5 healthy male volunteers aged 18-36 years old. Each sample comprised of approximately 10 $\mathrm{ml}$ of blood. A total of 15 samples (3 samples from each donor) were collected in order to complete the different experiments.

The heparinised blood was fractioned by centrifugation with Ficoll-Paque (Pharmacia, Upsala, Sweden) and subjected to sedimentation with dextran. This separation resulted in the formation of a PMN leukocyte sediment and an MN leucocyte layer at the Ficoll-Paque interface. This procedure resulted in preparations of $95 \%$ pure MN and PMN cells. MN and PMN cells were resuspended in PBS (phosphate buffered saline - pH 7.4) and washed. Resulting suspensions were adjusted to a concentration of $2 \times 10^{6}$ cells $/ \mathrm{mL}$ [35].

One millilitre suspensions comprising leukocytes (2 $\times 106 / \mathrm{mL})$ and amoebae $(1 \times 106 / \mathrm{mL})$ in PBS were placed in $15 \mathrm{~mL}$ Falcon tubes. The tubes were briefly filled to $95 \%$ of their capacity with PBS and each suspension of leucocytes (either MN or PMN) and amoebae was then pelleted and resuspended in $1 \mathrm{~mL}$ of PBS. The tubes were then shaken at $37^{\circ} \mathrm{C}$ for $60 \mathrm{~min}-$ utes to allow the leucocytes to interact with the trophozoites. Assays with the MN and PMN cells were adapted from a previously published protocol [35]. To evaluate possible melatonin effects on amoebae and leukocytes, the drug was added to the incubation medium at a concentration of $100 \mathrm{ng} / \mathrm{mL}$. This is considered to be a pharmacological dose [36] and is generally used to evaluate cellular activation [37].

Phagocytosis was interrupted by incubating the tubes on ice for $10 \mathrm{~min}$. The leukocytes and trophozoites were then stained with $200 \mu \mathrm{l}$ of acridine orange $(14.4 \mathrm{mg} / \mathrm{L})$ for two minutes and washed twice in ice-cold PBS [38]. Indices of adherence, ingestion and death of the trophozoites and leukocytes were determined by fluorescence microscopy (TIM-4000, Germany) and compared with controls performed under the same conditions without the addition of melatonin. One hundred amoebae were counted per slide.

Superoxide release $\left(\mathrm{O}_{2}{ }^{-}\right)$was measured by reducing cytochrome C (Sigma) as previously described [39] and in order to determine the concentration of the enzyme superoxide dismutase (SOD), the adapted protocol [40].

An unpaired t test was used to analyse differences in leukophagocytosis between the two groups. Differences were considered to be statistically significant when the $p$ value was lower than 0.05 . 


\section{Acknowledgements}

The authors are very grateful to João da Costa Viana for technical assistance. This work was supported by a scholarship (PhD) from CNPq (Conselho Nacional de Desenvolvimento Científico e Tecnológico) and also received financial assistance from the Foundation for Research of the State of Mato Grosso (FAPEMAT - 299032/2010), Brazil.

\section{Author details}

'Department of Parasitology, Institute of Biological Sciences, Universidade Federal de Minas Gerais, Belo Horizonte, Minas Gerais, Brazil. ${ }^{2}$ Institute of Health Sciences, Centro Universitário do Planalto de Araxá, Araxá, Minas Gerais, Brazil. ${ }^{3}$ Department of Biochemistry, Faculty of Medicine, Universidade de São Paulo, Ribeirão Preto, São Paulo, Brazil. ${ }^{4}$ Department of General Pathology, Institute of Biological Sciences, Universidade Federal de Minas Gerais, Belo Horizonte, Minas Gerais, Brazil. ${ }^{5}$ Institute of Biological Sciences and Health, Universidade Federal do Mato Grosso, Pontal do Araguaia, Mato Grosso, Brazil.

\section{Authors' contributions}

ACFB and MAG conceived the study. FMSO, MVC and MAG carried out the experiments in vivo. ACFB, JLF, ELF and ACHF carried out the experiments in vitro. All authors participated in the study design, analysis of the results, drafted the manuscript and have given final approval of the version to be published.

\section{Competing interests}

The authors declare that they have no competing interests.

Received: 11 February 2011 Accepted: 18 April 2011

Published: 18 April 2011

\section{References}

1. Cassone VM: Effects of melatonin on vertebrate circadian systems. Trends Neurosci 1990, 13:457-464.

2. Poon AM, Liu ZM, Pang CS, Brown GM, Pang SF: Evidence for a direct action of melatonin on the immune system. Biol Signals 1994, 3:107-17.

3. Wajs E, Kutoh E, Gupta D: Melatonin affects proopiomelanocortin gene expression in the immune organs of the rat. Eur J Endocrinol 1995, 133:754-760.

4. Guerrero JM, Reiter RJ: A brief survey of pineal gland-immune system interrelationships. Endocr Res 1992, 18:91-113.

5. del Gobbo V, Libri V, Villani N, Calio R, Nistico G: Pinealectomy inhibits interleukin-2 production and natural killer activity in mice. Int $J$ Immunopharmacol 1989, 11:567-573.

6. Giordano M, Palermo MS: Melatonin-induced enhancement of antibodydependent cellular cytotoxicity. J Pineal Res 1991, 10:117-121.

7. Pioli C, Caroleo MC, Nistico G, Doria G: Melatonin increases antigen presentation and amplifies specific and non specific signals for T-cell proliferation. Int J Immunopharmacol 1993, 15:463-468.

8. Konakchieva R, Kyurkchiev S, Kehayov I, Taushanova P, Kanchev L: Selective effect of methoxyindoles on the lymphocyte proliferation and melatonin binding to activated human lymphoid cells. J Neuroimmunol 1995, 63:125-132.

9. Morrey KM, McLachlan JA, Serkin CD, Bakouche O: Activation of human monocytes by the pineal hormone melatonin. J Immunol 1994 , $153: 2671-2680$

10. Lissoni P, Pittalis S, Brivio F, Tisi E, Rovelli F, Ardizzoia A, Barni S, Tancini G, Giudici G, Biondi A, Conti A, Maestroni G: In vitro modulatory effects of interleukin-3 on macrophage activation induced by interleukin-2. Cancer 1993, 71:2076-2081.

11. Lopez-Gonzalez MA, Calvo JR, Osuna C, Rubio A, Guerrero JM: Melatonin potentiates cyclic AMP production stimulated by vasoactive intestinal peptide in human lymphocytes. Neurosci Lett 1992, 136:150-152.

12. França EL, Feliciano ND, Silva KA, Ferrari CK, Honorio-França AC Modulatory role of melatonin on superoxide release by spleen macrophages isolated from alloxan-induced diabetic rats. Bratis/ Med J 2009, 110:517-522

13. França EL, Pereira A Jr, Oliveira SL, Honorio-França AC: Chronoimmunomodulation of melatonin on bactericidal activity of human blood phagocytes. Int J Microbiol 2009, 6:1-13.
14. WHO: Entamoeba taxonomy. Bull World Health Organ 1997, 75:291-294.

15. Olivos-García A, Nequiz-Avendaño M, Tello E, Martínez RD, GonzálezCanto A, López-Vancell R, García de León MC, Montfort I, Pérez-Tamayo R: Inflammation, complement, ischemia and amoebic survival in acute experimental amoebic liver abscesses in hamsters. Exp Mol Pathol 2004, 77:66-71.

16. Baltaci AK, Mogulkoc R, Turkoz Y, Bediz CS, Ozugurlu F: The effect of pinealectomy and zinc deficiency on nitric oxide levels in rats with induced Toxoplasma gondii infection. Swiss Med Wkly 2004, 134:359-363.

17. Baltaci AK, Mogulkoc R, Bediz CS, Pekel A: Effects of zinc deficiency and pinealectomy on cellular immunity in rats infected with Toxoplasma gondii. Biol Trace Elem Res 2005, 104:47-56.

18. Avunduk AM, Avunduk MC, Baltaci AK, Moğulkoç R: Effect of melatonin and zinc on the immune response in experimental Toxoplasma retinochoroiditis. Ophthalmologica 2007, 221:421-425.

19. Hotta CT, Markus RP, Garcia CR: Melatonin and N-acetyl-serotonin cross the red blood cell membrane and evoke calcium mobilization in malarial parasites. Braz J Med Biol Res 2003, 36:1583-1587.

20. Budu A, Peres R, Bueno VB, Catalani LH, Garcia CR: N1-acetyl-N2-formyl-5methoxykynuramine modulates the cell cycle of malaria parasites. J Pineal Res 2007, 42:261-266.

21. Santello FH, Frare EO, dos Santos CD, Toldo MP, Kawasse LM, Zucoloto S, do Prado JC Jr: Melatonin treatment reduces the severity of experimental Trypanosoma cruzi infection. J Pineal Res 2007, 42:359-363.

22. Bracha $R$, Nuchamowitz $Y$, Leippe $M$, Mirelman D: Antisense inhibition of amoebapore expression in Entamoeba histolytica causes a decrease in amoebic virulence. Mol Microbiol 1999, 34:463-472.

23. Stanley SL Jr: Amoebiasis. Lancet 2003, 22:1025-1034.

24. Costa CA, Nunes AC, Ferreira AJ, Gomes MA, Caliari MV: Entamoeba histolytica and E. dispar trophozoites in the liver of hamsters: in vivo binding of antibodies and complement. Parasit Vectors 2010, 3:23.

25. Srinivasan V, Spence DW, Moscovitch A, Pandi-Perumal SR, Trakht I, Brown GM, Cardinali DP: Malaria: therapeutic implications of melatonin. J Pineal Res 2010, 48:1-8.

26. Soliman MF, El Shenawy NS, El Arabi SE: Schistosoma mansoni: melatonin enhances efficacy of cercarial and soluble worm antigens in the induction of protective immunity against infection in the hamster. Exp Parasitol 2008, 119:291-295.

27. Garcia CR, Markus RP, Madeira L: Tertian and quartan fevers: temporal regulation in malarial infection. J Biol Rhythms 2001, 16:436-443.

28. Jarumilinta R, Kradolfer F: The toxic effect of Entamoeba histolytica on leucocytes. Ann Trop Med Parasitol 1964, 58:375-381.

29. Guerrant RL, Brush J, Ravdin Jl, Sullivan JA, Mandell GL: Interaction between Entamoeba histolytica and human polymorphonuclear neutrophils. J Infect Dis 1981, 143:83-93.

30. Oliveira LG, Kuehn CC, Santos CD, Toldo MP, do Prado JC Jr: Enhanced protection by melatonin and meloxicam combination in experimental infection by Trypanosoma cruzi. Parasite Immunol 2010, 32:245-251.

31. Diamond LS, Harlow DR, Cunnick CC: A new medium for the axenic cultivation of Entamoeba histolytica and other Entamoeba. Trans R Soc Trop Med Hyg 1978, 72:431-432

32. Williams GAH: Experimental hepatic amoebiasis and its application to chemotherapeutic studies. Br J Pharmacol Chemother 1959, 14:488-492.

33. Vaughan $G M$, Mason AD Jr, Reiter RJ: Serum melatonin after a single aqueous subcutaneous injection in Syrian hamsters. Neuroendocrinology 1986, 42:124-127.

34. Jayanthi M, Raveendran R, Basu D: Role of melatonin against oxidative tissue damage induced by Cleistanthus collinus in rat brain. Indian J Med Res 2009, 130:467-474

35. Honorio-França AC, Launay P, Carneiro-Sampaio MM, Monteiro RC: Colostral neutrophils express Fc alpha receptors (CD89) lacking gamma chain association and mediate noninflammatory properties of secretory IgA. J Leukoc Biol 2001, 69:289-296.

36. Juszczak M, Stempniak B: The effect of melatonin on suckling-induced oxytocin and prolactin release in the rat. Brain Res Bull 1997, 44:253-258.

37. Pei $M, H e F$, Wei $L$, Rawson A: Melatonin enhances cartilage matrix synthesis by porcine articular chondrocytes. J Pineal Res 2009, 46:181-187.

38. França-Botelho AC, Honório-França AC, França EL, Gomes MA, CostaCruz JM: Phagocytosis of Giardia lamblia trophozoites by human colostral leukocytes. Acta Paediatr 2006, 95:438-443. 
39. Pick E, Mizel D: Rapid microassays for the measurement of superoxide and hydrogen peroxide production by macrophages in culture using an automatic enzyme immunoassay reader. J Immunol Methods 1981, 46:211-226.

40. Crouch RK, Gandy SE, Kimsey G, Galbraith RA, Galbraith GM, Buse MG: The inhibition of islet superoxide dismutase by diabetogenic drugs. Diabetes 1981, 30:235-241.

doi:10.1186/1756-3305-4-62

Cite this article as: França-Botelho et al:: Melatonin reduces the severity of experimental amoebiasis. Parasites \& Vectors 2011 4:62.

Submit your next manuscript to BioMed Central and take full advantage of:

- Convenient online submission

- Thorough peer review

- No space constraints or color figure charges

- Immediate publication on acceptance

- Inclusion in PubMed, CAS, Scopus and Google Scholar

- Research which is freely available for redistribution

Submit your manuscript at www.biomedcentral.com/submit 